\title{
E AI, ESTÁ DIGITAL, ESTÁ FAVORÁVEL? A CONCILIAÇÃo PRÉ PROCESSUAL NO TRIBUNAL DE JUSTIÇA DO ESTADO DO RIO DE JANEIRO.
}

\author{
Luciane Mara Correa Gomes ${ }^{1}$
}

\section{Resumo:}

Os mecanismos de resolução de conflitos eletrônicos auxiliam a ruptura da acessabilidade a prestação jurisdicional encurtando as fronteiras do conflito social e o espaço físico dos tribunais. O projeto conciliação pré-processual, na forma eletrônica, onde o reclamante apresenta sua mazela diretamente ao prestador de serviço ou fornecedor. O problema apontado é a sua funcionalidade como mecanismo para solucionar conflitos, em regra, repetitivos. A partir dos dados do Tribunal de Justiça Fluminense, a partir da sua instalação, buscando delimitar a atuação do projeto. Com marco teórico em Cappelletti, Bastos e Greco, por método bibliográfico e documental para a construção.

Palavras-chave: Acesso à justiça; Poder Judiciário; Processo Eletrônico.

\section{AND SO, IS IT DIGITAL, IS IT FAVORABLE? THE PRE-PROCEEDING CONCILIATION IN THE COURT OF JUSTICE OF THE STATE OF RIO DE JANEIRO.}

\begin{abstract}
:
Electronic dispute resolution mechanisms help to break accessibility to judicial performance by shortening the boundaries of social conflict and court physical space. The pre-procedural conciliation project, in electronic form, where the claimant presents his complaint directly to the service provider or supplier. The problem pointed out is its functionality as a mechanism to solve conflicts, as a rule, repetitive. From the data of the Fluminense Court of Justice, from its installation, seeking to delimit the performance of the project. With theoretical framework in Cappelletti, Bastos and Greco, by bibliographical and documentary method for the construction.
\end{abstract}

Keywords: Access to justice; Judicial branch; Electronic process.

\section{INTRODUÇÃO}

A existência do confronto entre dois binômios a eficiência e a velocidade tem tomado conta das conversações existente no Poder Judiciário a despeito da inserção de tecnologias da informação na estrutura processual, como alternatividade a problemas de ordem estrutural que deve ser analisado sob o signo da verificação de que a partir do volume de processos em

\footnotetext{
${ }^{1}$ Mestre em Direito Público e Evolução Social (UNESA). Especialista em Direito Processual Civil (UCAM). Bacharel em ciências jurídicas e sociais (UFRJ). Advogada. Professora Auxiliar (UNISUAM). lucianemara@uol.com.br.
} 
tramitação, está o Estado deixando de prestar o atendimento de forma eficiente ao conflito social existente.

Noutro giro, outro problema de ordem pessoal, uma vez que com o acesso da população a mecanismos de facilitação da camada menos privilegiada economicamente a este serviço estatal, há um desalinho na rotina de procedimentos, apontando que na esfera dos cartórios e das varas, o quantitativo de serventuários não acompanhou o fluxo de processos distribuídos, resolvidos e pendentes, fenômeno não observado apenas nos juizados especiais cíveis, onde a demanda, em regra, é de baixa complexidade e, geralmente, de natureza consumerista.

Os impactos poderão ser sentidos com estas dualidades, sendo que, num primeiro momento, é possível diagnosticar que a população vai ter com a demora na entrega da prestação jurisdicional um descrédito no serviço prestado pelo Poder Judiciário; num segundo ponto, vislumbra-se que com a solução almejada, processos pela via eletrônica, há um afastamento da camada desguarnecida de conhecimento de tecnologias da informação. Não sendo forçoso apontar que o acesso será legado a uma parcela da sociedade que possui os equipamentos e recursos mais avançados, isto por que o desenvolvimento destas tecnologias traz, em seu conjunto, benefícios e oportunidade para quem está preparando - técnica e materialmente - para se destacar no acesso a esta modalidade de prestação jurisdicional.

Neste contexto, pode-se identificar que o pergil da conciliação pré processual é um balcão de Direitos às avessas, pois permanece o desequilíbrio entre consumidor e prestador de serviços, posto que o papel do Poder Judiciário não está em decidir, mas sim colocar as partes a desenvolver as técnicas de resolução do conflito de forma que as próprias interessadas venham a conjuntamente atingir o ponto de consenso.

O problema reside no fato de que esta modalidade de exercício do acesso ao judiciário torna-se comprometida por permear valores socioculturais, étnicos e interpessoais, onde um dos interessados e que é a parte fragilizada da relação jurídica ainda não consegue atingir, permanecendo em condições de desigualdade.

Em terras brasileiras, o acesso à justiça foi objeto de estudo a partir dos anos noventa e se percebe que a inserção do processo eletrônico tem uma década de existência caminhando a 
passos limitados ao conhecimento dos usuários e das tecnologias da informática com o precário tráfego de dados. Por seu turno, a codificação processual civil insere o instituto da conciliação antecedendo a demanda judicial com o objetivo de solucionar os conflitos que, em sua grande maioria, tem natureza consumerista.

Com isto, compreender as dificuldades para o exercício no Brasil da conciliação pré processual, que foi constituída a partir do modelo europeu de resolução das disputas por meios digitais, é a hipótese mais aplicável para alcançar a efetividade do método. Especificamente, se desenvolvendo pelos dados do Tribunal de Justiça do Estado do Rio de Janeiro, a partir da sua instalação, buscando delimitar a atuação do projeto; identificar a proteção constitucional à igualdade de tratamento entre litigantes e ao analisar os dados do referido projeto comparar as práticas do projeto europeu.

O estudo terá como marco teórico o estudo da conciliação pré processual fixando como ponto inaugural a instalação do projeto no Tribunal de Justiça Fluminense e a sua funcionalidade como mecanismos alternativo pela visão de Mauro Cappelletti e Mauro Garth e a apresentação de alguns conceitos por Aurélio Wander Bastos, no que se refere ao campo judiciário servindo de escopo a pesquisa, no que tange a entrega das prestações jurisdicionais e a condição estrutural dos tribunais a partir da nova codificação pela ótica de Luiz Guilherme Marinoni e de Leonardo Greco, o que lhe confere uma metodologia de análise documental e bibliográfica no que se destina a justificar a escolha por entender a importância da pesquisa no desenvolvimento das rotinas do Poder Judiciário e os resultados revertidos para a sociedade.

\section{UMA ANÁLISE DO PROJETO CONCILIAÇÃO PRÉ PROCESSUAL}

O acesso à prestação jurisdicional, com a sua elevação a condição de direito fundamental na Constituição de 1988, tem sido recorrentemente objeto de estudo em virtude da larga distância entre a sua eficiência e a situação presentada nos tribunais brasileiros. Importante recordar que a grande parte das reformas processuais do último quarto do século passado não conseguiu conferir ao Poder Judiciário uma zona de conforto para decidir e solucionar conflitos entre os indivíduos.

Sob a chancela de ter sido o grande responsável pelo assoberbamento dos tribunais, as demandas de massa não repousam sobre elas a condição de culpadas pela demora na entrega 
da prestação jurisdicional, talvez seja um ponto fora da curva, que aqui cabe nominar como a falta de condições igualitárias para o seu acesso. É provável que Piero Calamandrei (2004, p. 27), em um ciclo de palestras conferidas na Universidade de Pádua, já tivesse o olhar de que a certeza do direito e a igualdade dos cidadãos perante a lei que antes eram conquistas preciosas, hoje, estão cada vez mais em perigo.

Outrora, o que estivesse identificado como conceito de acesso à justiça aquela garantia de direito formal do individuo, constituísse tão somente mais uma afronta aos direitos do homem, uma vez que sem possuir a condição pelo Estado em ter meios para recompor a violação daqueles, seria uma vertente mais cruel de injustiça. Tendências fomentadas pelo desenvolvimento da sociedade no século passado a partir da redução de fronteiras, alargamento de práticas comerciais e reconhecimento de direitos muito mais coletivos do que propriamente individualizados, surgindo novos direitos a partir do alargamento das relações sociais.

Possibilitar e facilitar o acesso à justiça foi e tem sido uma preocupação e uma construção constante nas sociedades modernas, principalmente após o reconhecimento da sua posição de direito fundamental e de direitos humanos, sendo objeto de estudo de Mauro Cappelletti e Bryant Garth, do qual se extraem três vertentes para alcance deste acesso com igualdade de armas: o acesso pela coletivização de direitos; a construção de métodos alternativos para decidir causas judiciais e a instrumentalização do acesso a quem não possua condições técnicas e financeiras para a litigância.

A pesquisa busca, nos mecanismos alternativos, as vantagens de conciliação, evidenciando seus elaboradores, dois eixos fundamentais o custo do litígio e a sobrecarga dos tribunais. Apontando que a satisfação das partes envolvidas se operacionaliza e acomoda o conflito com maior facilidade do que uma decisão judicial, inaugurando outras análises a partir do estabelecimento de um conceito diferenciado para as demandas judiciais que é o ganha-ganha em oposição a dualidade vencedor-vencido (CAPPELLETTI, GARTH, 1988, 84), concretizando ainda aquilo que será contido nos debates acadêmicos do início deste século que é a importância na restauração dos relacionamentos prolongados e sua utilidade nesta dinâmica de conservação. 
Aurélio Wander Bastos (2001, p. 121) já assinalava a importância de identificar as causas de insucesso das demandas no Poder Judiciário, dividindo-as em dois blocos decisórios aqueles conflitos que causam sobrecarga de modo quantitativo, abalando o potencial de decisão por fatores internos. Este ponto pode ser adaptado ante as novas exigências, por ser um aspecto estrutural. Todavia, há demandas que são qualitativamente superiores ao potencial de decisão do Judiciário, cujos vínculos são complexos e contínuos, sofrendo reflexos na dificuldade de adaptação aos novos padrões sociais.

É necessário demonstrar que o conflito poderá ser envolto em formas de profundidade, que poderá ser entendida a partir das partes integrantes nesta relação social e o grau de transformação na relação existente. Apontar que o conflito possa ter uma profundidade acentuada significa sinalizar que o conflito sugere a alteração do vínculo existente entre as partes. Noutro pólo, é de pequena profundidade quando não afeta a estrutura de relação entre os conflitantes. Num terceiro ponto, há grande conflituosidade, quando se pretende a eliminação do vínculo estrutural entre as partes (BASTOS, 2001, p. 123-124).

Mais uma vez, os pesquisadores apontam que a essência da conciliação é a redução do congestionamento do judiciário, carece de certificar que os resultados efetivamente são de êxito, apontando assim que a conciliação não foi instituída para ser a taboa de salvação para o problema do excesso de processos, mas sim um caminho para a entrega célere da resposta por iniciativa dos próprios agentes sociais.

Boaventura de Souza Santos apontou diversas saídas para a sobrecarga dos tribunais, desde que haja relação direta como tempo nos processos. Para o autor além de ser variável em cada país, deve ainda causar naquele que busca o tribunal para resolver seu problema o sentimento de desconfiança na eficácia da justiça, e tais tentativas passam pela informalização da justiça, reapetrechamento dos tribunais com recursos humanos e infraestruturas, automatização, novas tecnologias de comunicação e informação, criação de tribunais especiais para a pequena litigação de massa, reformas processuais (2007, p. 26).

Neste ponto, a morosidade é prejudicial não só para as partes interessadas como também para a qualidade no funcionamento dos tribunais. Não é cabal aceitar que em nome de eliminar a sobrecarga de trabalho, o excesso de burocracia, o positivismo e o legalismo, 
sejam adotadas condutas que vão gerar efeitos nefastos e que não traduzam em justiça cidadã, tão somente terá uma justiça mais rápida.

É plausível considerar que a conciliação possa assumir, como método ágil, informal e célere no sentido de contenção de um número cada vez maior de demandas, podendo haver ainda, a redução de custos com a sua realização virtual, hipóteses que serão avaliadas no item que se segue.

\section{ACESSO À JUSTIÇA PELA CONCILIAÇÃO}

Os conflitos sociais, pensados a partir de uma perspectiva de infração a normas jurídicas, encontram-se num patamar de imposição ao crivo do Poder Judiciário como regra impositiva da pacificação social. Decidir um conflito social dentro de um estado democrático de direito ultrapassa o senso medianeiro dos conflitantes. Muito embora há relações que se perpetuam no tempo e no espaço, somente o Estado, ao regrar estas relações individuais e supraindividuais, irá promover a escolha mais lógica a violação trazida para decisão.

O Estado democrático traz em seu substrato o sentido da igualdade formal, como equilíbrio aos indivíduos, uma vez que a decisão judicial será permeada não só do espírito da lei, mas também a partir de uma razoabilidade inerente a reflexão do juiz acerca do caso ali analisado, pois a justiça é a plena realização do bem estar, uma vez que a justiça traz a felicidade ao homem.

A modernidade trouxe para o indivíduo um cabedal de conceitos que são ajustáveis a sociedade como indivíduo, sociedade, cidadania e classes sociais. Estes conceitos são aplicados pelo Poder Judiciário a partir das notas introdutórias da passagem de uma sociedade tipicamente artesanal com uma economia centrada nas pequenas oficinas, para a centralização nas fábricas.

É fato que, a partir das Revoluções Inglesa e Francesa, a sociedade foi conduzida a adaptar aos processos de produção em massa que tornaram a economia, o direito e a administração ciências conectadas com a sociedade. Esta posição é pautada no fenômeno que alavancou a circulação de bens e mercadorias, através de processos de globalização, onde as fronteiras foram estreitadas, a título de exemplificação, pelo surgimento de blocos 
econômicos e acelerado pela rede mundial de computadores onde a interface entre consumidor e fornecedor foi singularizada pelos contratos eletrônicos.

No Brasil, as relações advindas do consumo em massa passaram a ser regradas pelo Código de Defesa do Consumidor, instrumento de vanguarda e inspirador de outros marcos legislativos, a partir de 1990, veio a introduzir conceitos como direitos difusos e coletivos, inversão do ônus da prova para a parte hipossuficiente, proteção efetiva ao consumidor e criação de juizados especiais de pequenas causa de varas especializadas para a solução de litígios de consumo.

Desta forma, o consumidor, como elo mais frágil da cadeia de consumo, passou a dispor do acesso à justiça através dos juizados especiais de pequenas causas. Estes juizados que haviam sido criados pela Lei Federal 7.244, de 7 de novembro de 1984, vieram a ser substituídos, pela Lei Federal n. 9.099 de 26 de setembro de 1995, pelos juizados especiais cíveis

Manter o exercício da satisfação da pretensão a receber do Estado uma decisão capaz de reparar a violação ao seu direito é uma prestação bastante complexa para o indivíduo que recorre à jurisdição para obter esta garantia fundamental. Assim, ao tentarmos identificar que cumpre ao Poder Judiciário na hipótese de receber uma sobrecarga de demandas em patamar superior ao seu potencial de decisão - seja qualitativa, seja quantitativa - faz a adequação necessária a esta nova exigência, sob pena de sofrer mudanças desintegradoras.

Esta posição é assumida por Aurélio Wander Bastos (2001, p. 122) ao fazer a abordagem da estrutura interna da Administração da Justiça, sintetizando que cabe a máquina administrativa do Judiciário efetuar levantamentos, promover aprendizados e adaptar aos novos padrões de comportamento, alterando aqueles que interfiram na sua avaria.

Não é forçoso assegurar que diversos movimentos no sentido de reformar a legislação processual tem sido a preocupação mais pontual uma vez que o cidadão pretende receber de forma proporcional a razoável duração do processo. Não obstante seu conceito aberto, é a partir da jurisprudência da Corte Europeia de Direitos Humanos que se encontram critérios 
para identificar o grau de razoabilidade: a complexidade da causa; o comportamento das partes e o comportamento do juiz na condução do processo ${ }^{2}$.

Como constituir um método que além de tornar mais célere e mais eficiente sem deixar de preservar a proteção constitucional das garantias processuais fundamentais, assim como fomentar a participatividade dos agentes envolvidos no processo, contribuindo para a concretização das necessidades inseridas na comunidade globalizada, sistemática em constante evolução.

Daí pode se extrair o pensamento e realizar que impor ao individuo um método de resolução de conflitos por meio digital, de algum modo, é capaz de a diretriz da codificação processual violar o princípio da paridade de armas e, para tanto, precisa-se estabelecer um conceito para identificá-la e emitir uma posição acerca da pratica dos atos de modo eletrônico garantir a igualdade aos litigantes. Para compreendermos o alcance do princípio da igualdade de armas, é salutar recorrer a Marinoni, Arenhart e Mitidiero (2015, p. 105).

O direito à igualdade processual - formal e material - é o suporte do direito à paridade de armas no processo civil (Waffengleichheit, parità delle armi, ègalité des armes). O processo só pode ser considerado justo e as partes dispõem das mesmas oportunidades e dos mesmos meios para dele participar. Vale dizer; se dispõem das mesmas armas, se dispõem de paridade de tratamento. Trata-e de exigência que obviamente se projeta sobre o legislador sobre o juiz: há dever de estruturação e condução do processo de acordo com o direito à igualdade e à paridade de tratamento. Como facilmente se percebe, a igualdade - e a paridade de tratamento e de armas nela implicada constitui pressuposto para efetiva participação das partes no processo e, portanto, é requisito básico para plena realização do direito ao contraditório (art. $7^{\circ}$, in fine, $\mathrm{CPC}$ ).

Humberto Dalla Bernardina de Pinho (2015, p.57) sinaliza que tanto o direito material quanto o direito processual não podem deixar de atender aos anseios sociais, sem perder sua

${ }^{2}$ Corte Europeia de Direitos Humanos. Caso Neumeister VS Áustria, 1968. MARINONI, Luiz Guilherme. Arenhart Sergio Cruz. Mitidiero, Daniel. O novo processo civil. São Paulo: Revista dos Tribunais, 2015, 172. 
essência, inserindo o acesso à justiça numa ordem civil constitucional para assegurar a devida proteção as grandes carências e necessidades da sociedade de massa.

Para que se possa construir um método que confira aos cidadãos a eficiência e a solução mais rápida para o conflito, é importante assegurar que este acesso atenderá à ordem jurídica justa. Paulo Cesar Pinheiro Carneiro (2007, p. 58), em pesquisa institucional realizada pela Universidade do Estado do Rio de Janeiro e a Universidade Estácio de Sá, verbalizou que devem ser construídas dinâmicas que protejam quatro princípios que devem estar contidos no desenho institucional da decisão proferida pelo campo judiciário: a acessabilidade, a operosidade, a utilidade e a proporcionalidade.

É necessário compreender a acessibilidade como a etapa que assegure a qualquer cidadão o instrumento eficaz para estar em juízo e ainda que opte por outro que não seja excluída a prestação jurisdicional. Por operosidade, a atuação ética daqueles que atuam no campo judiciário; a utilidade com o fim de promover a entrega do bem da vida almejado de forma rápida sem sacrifícios exorbitantes ao vencido e a proporcionalidade que privilegia o interesse mais precioso e que satisfaça a uma gama maior de pessoas.

Métodos que podem ser alcançados por instrumentos e meios processuais corretos que priorizem a atitude conciliatória. Todavia, uma cautela deve ser perseguida é quanto a possibilidade de tentativa de conciliação se transformar em um pretexto para retardar o andamento ou a solução, devendo ser seguida a risca a orientação de Leonardo Greco (2015, p.24):

O uso dos meios alternativos é desejável, mas deve ter como pano de fundo uma justiça estatal eficiente e confiável, para que a escolha dos cidadãos entre uma ou outra via se dê em busca do meio que mais bem tutele os interesses em jogo e para que aquele que optarem pelos primeiros se sintam seguros de que a justiça estatal estará sempre de portas abertas para coibir os abusos ou erros manifestos que ocorrerem na sua atuação.

A legislação processual civil brasileira introduziu em março de 2016, através da Lei Federal n. 13.105, a dinâmica da conciliação pré-processual no intuito de reduzir o tempo de tramitação do processo, a partir das fases constante do artigo 334, indicando que será vigida pelos princípios da independência, da imparcialidade, da autonomia da vontade, da confidencialidade, da oralidade, da informalidade e da decisão informada. 
É sustentável apontar que esta autonomia de vontade das partes está parcialmente comprometida no momento em que a eles, em caso de absenteísmo, é considerado ato atentatório à dignidade da justiça sancionado com multa de ate dois por cento da vantagem econômica pretendida ou do valor da causa. Não obstante, compelir a parte a tomar parte quando a lei a define como obrigatória foge ao bom senso.

Desta forma, se o objetivo da conciliação é obter como resultado a ponderação pelos interessados, compondo não se pode imputar o encargo sob pena de se tornar apenas uma fase processual que culminará na procrastinação do processo. Não obstante a esta evidência aqui apontada, o Tribunal de Justiça do Estado do Rio de Janeiro introduziu o Centro Permanente de Conciliação dos Juizados Especiais Cíveis, tópico do item que se segue.

\section{A CONCILIAÇÃo PRÉ PROCESSUAL NO TRIBUNAL DE JUSTIÇA FLUMINENSE}

Importante interface com os direitos fundamentais do individuo é garantir que o mesmo possa ter, gozar e usufruir do acesso à justiça; o acesso à prestação jurisdicional efetiva e o acesso à defesa. Em todos os níveis mencionados há interferência direta no processo, em especial na modalidade digital, inserido no ordenamento jurídico brasileiro pela Lei Federal 11.419 de 19 de dezembro de 2006, tomou como meta a redução de problemas estruturais, de recursos humanos, mas também é preciso lançar um olhar sobre um impasse que pode comprometer o bom funcionamento do acesso digital que é o aspecto cultural.

Com a reforma da legislação processual, a Lei Federal n. 13.105, de 16 de março de 2015, consolidando as diretrizes da legislação especial, trouxe para a sociedade a prática de atos processuais por meio eletrônico, cujo objetivo é trazer celeridade ao processo, como meta de romper a morosidade do Poder Judiciário em entregar a prestação jurisdicional em consonância com a preleção constitucional de razoável duração do processo, que, em algumas situações, não se oferta o serviço efetivo e eficaz para o indivíduo por razões plúrimas. 
Por seu turno, cumpre pontuar que a tutela de direitos não se dá exclusivamente no campo individualista, não só pelo fato de ser o processo civil uma norma de ordem pública, como também ter reflexos para além da relação de direito privado nas quais os indivíduos em colisão de interesses estão envoltos. Uma das principais conquistas do século XXI, no campo da sociologia das organizações, é tornar o Poder Judiciário mais dinâmico, através da leitura dos resultados por ele apresentados, tomando como diretriz a estrutura do tribunal e os agentes sociais.

O trabalho recebe recorte para avaliar a necessidade de inserção digital da população, com o cuidado de que ao por em vigência uma norma que estabeleça o acesso à justiça por meio eletrônico, não haja o afastamento do indivíduo da prestação jurisdicional efetiva. Principalmente se este indivíduo não conseguir o acesso digital necessário ao pleno exercício da jurisdição, já que se o autor tem o direito de acesso à justiça, que deve ser o mais amplo possível, de outro, o réu tem o direito de se defender e de influir nas decisões do juiz (GRECO, 2015, p. 516). Imperiosa seria que o Estado adotasse políticas públicas destinadas à inclusão digital para que o excluído possa estar hábil a execução dos parâmetros mínimos de acessibilidade, dinamizando o acesso de todos a modernização do Poder Judiciário.

O processo não pode se modernizar apenas nas leis ou nas atitudes dos seus operadores; é preciso materializar de forma física e palpável o seu desenvolvimento No mundo globalizado e dinâmico, as novas tecnologias da informação são essenciais, por isso, o processo eletrônico veio com o objetivo de contribuir com o acesso de todos a uma ordem jurídica justa.

A informatização do Judiciário contribui de forma proficiente para que todas as ondas de desenvolvimento do aceso à Justiça se efetivem. A digitalização melhora a comunicação de atos em âmbito nacional e a defesa de interesses supraindividuais. A exemplo disso temos que há uma maior celeridade, na medida em que os atos de cartório deixam de tomar o tempo das varas;um menor valor das custas ou impostos uma vez que o processo eletrônico é mais barato e, principalmente, celeridade da resolução do conflito. (PINHO, 2015, p. 421-422).

Importante consideração a despeito da condição do excluído digitalmente é feita por Bruno Pires Malaquias (2003, p. 2), em especial no que tange a condição daquele que não domina o acesso à rede mundial de computadores e está em situação de marginalizado nas demais esferas da vida social, condição impregnada do conceito de qualidade de vida, ante a possibilidade de acesso à informação. 
Hoje, "navegar" é imprescindível, sobretudo, dominar as tecnologias de informação. Sem embargos, informação é poder. Diante de tais circunstâncias, o já estreito funil da exclusão ficou mais apertado. É de incontroverso saber que a Internet e o computador são ferramentas imprescindíveis para quem quer se inserir no mercado de trabalho. Isto porque, desde o balconista do supermercado até o dentista ou o advogado, a todos se impõe o uso da informática. Qualquer profissional precisa dominar as tecnologias de informação, seja ele quem for, esteja ele onde estiver. Hodiernamente, sem informação não há comunicação, o que resulta em exclusão, marginalização.

Com a inserção do mundo digital em todos os eixos da sociedade civil, não seria forçoso concordar que o Poder Judiciário ao incorporar o processo eletrônico precisa criar projetos e programas destinados a facilitar o acesso de todos os envolvidos em demandas judiciais. Se por um lado, o Brasil, com suas dimensões continentais, tem um vasto território, o que implica dizer diversidades estruturais, é necessário esclarecer que há múltiplas características, pendendo para cada unidade federativa com sua estrutura regional. Por esta razão, a pesquisa delimita seu conteúdo temporal, a partir da vigência do Código de Processo Civil, em 16 de março de 2016, para analisar as políticas implementadas para o acesso digital e a realização dos atos processuais por meio eletrônico.

Um problema apontado por Leonardo Greco (2015, p. 315) a despeito da implantação do processo eletrônico guarda estreita relação com a possível desigualdade entre os operadores do Direito.

Sobre a implantação do processo eletrônico, cabem as ressalvas anteriormente realizadas no estudo das citações quanto à autenticidade dos documentos eletrônicos e quanto à possível elitização da advocacia, bem como, aqui mesmo no capítulo as intimações, sobre as incertezas criadas pela sua implantação nos diversos tribunais e pelas perplexidades trazidas pelo Código de 2015, com disposições que introduzem algumas regras que complementam e modificam as da Lei n. 11.419 e muitas apresentam dificuldade de harmonização com o regime de intimações herdado do Código de 1973.

O temos é justificável, pois, no Estado do Rio de Janeiro, há estatísticas que atestam que possivelmente mais da metade de todos os processos existentes na justiça fluminense são patrocinados pela Defensoria Pública, que, até onde me é dado conhecer, não dispõe de equipamentos eletrônicos suficientes para atender a esse volume de demanda. 
Distante dessa realidade, o Superior Tribunal de Justiça, a partir de 03 de março de 2008, publica seus atos judiciais e administrativos no Diário de Justiça Eletrônico (DJe), em substituição ao periódico impresso.

No seu sítio, o STJ orienta os interessados sobre esse novo meio de comunicação dos atos processuais (www.stj.jus.br).

O Tribunal de Justiça do Rio de Janeiro instituiu na justiça estadual o Diário de Justiça eletrônico por meio da Resolução n. 10/2008, do seu Órgão Especial, e o processo eletrônico atualmente é regulado na Resolução n. $16 / 2009$.

Não se deve deixar de observar que na prática dos atos processuais não poderá impedir a participação efetiva das partes no processo nem deduzir quaisquer outras dinâmicas de acesso:

(...) os sistemas de automação processual devem respeitar a publicidade dos atos, o acesso e a participação das partes e de seus procuradores, inclusive nas audiências e sessões de julgamento, respeitas as garantias da disponibilidade, independência da plataforma computacional, acessibilidade e interoperabilidade dos sistemas, serviços, dados e informações que o Poder Judiciário administre no exercício de suas funções. (MARINONI, ARENHART e MITIDIERO, 2015, p. 247).

Algumas considerações são formuladas por Cunha, Bochenek e Cambi (2016, p. 482483) no que diz respeito ao desenvolvimento de tais técnicas.

Embora o Conselho Nacional de Justiça ainda trabalhe para a unificação e o aperfeiçoamento dos respectivos sistemas, o processo eletrônico já é uma realidade em vários ramos do Poder Judiciário e tem contribuído para a facilitação e a rapidez no desenrolar dos processos, porque conta com vantagem inegável que é a diminuição do tempo para a prática dos atos processuais. No Estado do Paraná, por exemplo, atualmente, todos os processos no âmbito do primeiro grau de jurisdição já se iniciam pelo sistema eletrônico do Projudi (Processo Judicial Digital). Trata-se de sistema de informática que reproduz todo o procedimento judicial em meio eletrônico, substituindo o registro dos atos processos realizados no papel por armazenamento e manipulação dos autos em meio digital.

O Tribunal de Justiça do Estado do Rio de Janeiro criou no ano de 2011, através da Resolução TJ/OE n. 20 de 18 de julho de 2011, o Centro Permanente de Conciliação. Este 
órgão recebeu, através do Projeto de Conciliação Pré Processual um volume de 2890 pedidos de submissão a meio alternativo de solução de conflito, no ano de 2013.

A metodologia de acesso ao projeto se dá pela remessa por correio eletrônico do pedido para tentar resolver o conflito, antecedendo a distribuição de processo, com a criação de um endereço eletrônico para os participantes. Verifica-se que trinta empresas integram, com a finalidade de desjudicializar os conflitos, a saber: Vivo, Claro, TIM, CEG, Itaú, Light, Oi/Telemar, Net, Casas Bahia, Ponto Frio, Sky, Ricardo Eletro, B2W, Americanas.com, Shoptime, Sou Barato, Submarino, Santander, Losango, HSBC, Bradesco, Citibank, Unimed, Brastemp. Universidade Estácio de Sá, gol. Amil, Samsung, Nextel e Britania.

Os resultados obtidos no ano de 2013 foram de $70 \%$ do acervo em acordos. A decisão proferida é um titulo executivo extrajudicial, que viabiliza, em caso de descumprimento, a natureza executiva. Neste mesmo período, o Tribunal de Justiça Fluminense teve a distribuição de quase 900 mil processos, com acervo de 500 mil pendentes.

Não obstante o fato de que as estatísticas do ano de 2011, que foram divulgadas no ano de 2013, um volume de mais de meio milhão de processos distribuídos, com o julgamento de mais de 600 mil, não houve até os dias de hoje a atualização pelo Tribunal dos relatórios para os anos seguintes, não sendo contributivo para a análise da sua eficiência.

Em face do quantitativo de casos submetidos ao Projeto Conciliação Pré Processual ainda seja tímida expressão, corresponde ao reforço do trabalho do campo judiciário para atingir a sustentabilidade, com a redução de gastos com insumos, recursos naturais e servidores públicos, como também fomentar a resolução do conflito sem incluir estes procedimentos na lista dos trinta mais litigantes.

\section{CONCLUSÃO}

É necessário destacar que o direito processual civil não está isolado na ciência do direito havendo estreita comunicação com a sociologia, em especial a sociologia das organizações, onde o campo judiciário exerce suas peculiaridades e merece a atenção da academia por ser o desaguar dos conflitos sociais. Como também por guardar estreitos laços com o direito constitucional recebe influência direta dos Direitos Humanos, uma vez que a 
vida digna que a pessoa humana almeja é aquela onde o Estado execute suas programações e atenda as necessidades individuais e coletivas.

No que tange ao Brasil, a partir da Constituição Cidadã, os direitos fundamentais passaram a conter parcelas mínimas de garantias ao bom funcionamento da via processual, como meio de garantir uma prestação jurisdicional eficaz e que possa saciar a fome e sede de justiça daquele que tem seu direito em rota de colisão ou ameaça, tanto o é que a duração razoável do processo foi transmutada de diversos tratados internacionais para a esfera constitucional com o fim de tornar o resultado prático pretendido pelo individuo que recorre ao Poder Judiciário tangível.

Com todas as modificações sociais ocorridas nas últimas décadas, em especial, a partir de 1980, a sociedade encontra-se massificada e estruturada a comandos repetitivos, inovadores e cada vez mais sob influência de novas tecnologias, refletido também no Poder Judiciário que passou a receber um volume maior de demandas para serem solucionadas.

Nesta estrutura, o acesso à Justiça restou prejudicado com a morosidade na tramitação dos processos, por existirem estruturas frágeis diante da acessibilidade e da operosidade, vez que o resultado da lide diante do volume exacerbado de demandas tem sua utilidade e sua proporcionalidade prejudicadas.

Seja pelo processo eletrônico, seja pelo processo físico, as contingências para a obtenção de uma prestação jurisdicional efetiva cruzam fronteiras que demandam recursos materiais e estruturais para a sua concretização, motivo determinante para que o Tribunal de Justiça do Estado do Rio de Janeiro instalasse , como método de solução alternativa de conflitos, a realidade o Projeto Pré Processual, com a finalidade de entregar uma prestação jurisdicional efetiva com o custo de recursos menos elevado possível.

Buscar a diminuição dos obstáculos ao acesso à justiça é um dos fatores que levaram o Tribunal de Justiça do Estado do Rio de Janeiro a implementar o Centro Permanente de Conciliação que, através do Projeto de Conciliação Pré Processual, busca melhorar a redução de custos, facilitando ainda aqueles litigantes de baixo nível econômico e educacional, que também prejudica os autores individuais, já que, por este canal, outras formas de assistência jurídica são viabilizadas aos jurisdicionados. 
É possível enxergar que o modelo tem pontos de contato com o encurtamento das barreiras de acesso à prestação jurisdicional primeiramente pela ruptura dos aspectos de uniformidades, segurança e desforço para a proteção do consumidor. Se pensar o debate da Justiça como meio de pacificação social, demarcar o termo é considerar que se tratada de uma virtude de dar a cada um, o direito que lhe pertence, inserindo nesta perspectiva de entregar a Justiça, com a redução não só de custos ambientais, mas também de acessibilidade aos indivíduos ao desenvolvimento da prestação.

\section{REFERÊNCIAS}

BASTOS, Aurelio Wander. Conflitos sociais e limites do Poder Judiciário. $2^{\text {a }}$ edição revista e atualizada. Rio de Janeiro: Lúmen Júris. 2001.

CALAMANDREI, Piero. A crise da justiça. Tradução de Hiltomar Martins Oliveira. Belo Horizonte: Editora LÍDER, 2004.

CARNEIRO, Paulo César Pinheiro. Acesso à justiça: juizados especiais cíveis e ação civil pública: uma nova sistematização da teoria geral do processo. Rio de Janeiro: Forense, 2007.

GRECO, Leonardo. Instituições de processo civil. Introdução do Direito Processual Civil. Volume I. 5 $5^{\text {a }}$ edição revista, atualizada e ampliada. Rio de Janeiro: Forense, 2015.

MARINONI, Luiz Guilherme; ARENHART, Sergio Cruz; MITIDIERO, Daniel. Novo curso de processo civil: tutela dos direitos mediante procedimento comum. Volume II. São Paulo: Revista dos Tribunais, 2015.

Novo código de processo civil comentado. São Paulo: Revista dos Tribunais, 2015.

PINHO, Humberto Dalla Bernardina de. Direito Processual civil contemporâneo. Volume I: teoria geral do processo. $6^{\text {a }}$ edição. São Paulo: Saraiva, 2015.

SANTOS, Boaventura de Souza. A sociologia dos Tribunais e a democratização da justiça. In: SANTOS, Boaventura de Souza. Pela mão de Alice. São Paulo: Cortez, 1985. 
Para uma revolução democrática da justiça. $3^{\text {a }}$ edição revista e ampliada. São Paulo: Cortez, 2007. 